\title{
APLICABILIDADE DA OZONIOTERAPIA NA ODONTOLOGIA: UMA REVISÃO DE LITERATURA
}

\author{
Leisle Veronica Prestes ${ }^{1}$ \\ Rafaela Feix Picinato Turci ${ }^{2}$ \\ Ana Caroline dos Santos Grunow ${ }^{3}$ \\ Heloisa Maria Peressin ${ }^{4}$ \\ Katiely Tecilla ${ }^{5}$ \\ Daniela de Cássia Faglioni Boleta-Ceranto 6
}

PRESTES, L. V.; TURCI, R. F. P.; GRUNOW, A. C. dos S.; PERESSIN, H. M.; TECILlA, K.; BOLETA-CERANTO, D. de C. F. Aplicabilidade da ozonioterapia na odontologia: uma revisão de literatura. Arquivos de Ciências da Saúde da UNIPAR, Umuarama, v. 24, n. 3, p. 203-208, set./dez. 2020.

RESUMO: A Ozonioterapia, método que utiliza a mistura gasosa de ozônio e oxigênio, é uma das Práticas Integrativas aprovadas pelo Ministério da Saúde. Atualmente é utilizada na Odontologia devido, principalmente, às suas características estruturais que permitem vastas aplicações. Essa Prática tem como principal objetivo os fins terapêuticos, por meio de propostas cada vez mais efetivas, que corroboram para técnicas e métodos capazes de propiciar tratamentos complementares a fim de curar e prevenir patologias inerentes à cavidade oral, contribuindo para a potencialização de resultados das técnicas já existentes. Em virtude da busca por técnicas complementares, a Ozonioterapia ganhou destaque e tem se mostrado efetiva e segura em diversas práticas odontológicas. O presente trabalho tem por objetivo, por meio de uma revisão de literatura, ressaltar as aplicabilidades do Ozônio $\left(\mathrm{O}_{3}\right)$ na área odontológica, explicitando meios de utilização e suas respectivas ações, bem como, as contraindicações frente às ocorrências que acometem a cavidade oral.

PALAVRAS-CHAVE: Ozonioterapia. Bactérias. Dentística. Reparação tecidual.

\section{APPLICABILITY OF OZONE THERAPY IN DENTISTRY: A LITERATURE REVIEW}

ABSTRACT: Ozone therapy, a method that uses a gaseous mixture of ozone and oxygen, is one of the Integrative Practices approved by the Brazilian Ministry of Health. It is currently used in dentistry mainly due to its structural characteristics that allow a wide range of applications. This Practice focuses on therapeutic purposes through increasingly effective proposals that corroborate techniques and methods capable of providing complementary treatments in order to cure and prevent pathologies inherent to the oral cavity, contributing to the potentiation of results from existing techniques. Due to the search for complementary techniques, ozone therapy has gained prominence and has proven to be both effective and safe in several dental practices. This work aims at highlighting the applicability of Ozone (O3) in the dental area through a literature review, explaining means of use and their respective actions, as well as the contraindications to occurrences that affect the oral cavity.

KEYWORDS: Ozone therapy. Bacterium. Dentistry. Tissue repair.

\section{Introdução}

Com o objetivo de promover a racionalização das ações de saúde e estimular alternativas inovadoras e socialmente contributivas, o Ministério da Saúde, a partir de 2006, iniciou a implantação das Práticas Integrativas e Complementares em Saúde (PICs), que têm se tornado opções promissoras no que tange às possibilidades de amenizar ou evitar patologias (BRASIL, 2006). Especificamente na Odontologia, o Conselho Federal de Odontologia (CFO) buscou incluir as PICs a fim de que o cirurgião-dentista (CD) fosse apto e ampliasse as possibilidades do atendimento odontológico, o que vêm se consolidando a partir da Resolução CFO 82/2008, que reconheceu o exercício pelo cirurgião-dentista das seguintes PICS: acupuntura, fitoterapia, terapia floral, hipnose, homeopatia e laserterapia (BRASIL, 2015).

Em decorrência disso, após essas implantações, houve a inserção de novas práticas, e uma delas se refere à Ozonioterapia, reconhecida por meio da Resolução CFO$166 / 2015$, como um procedimento odontológico, integrado às PICs já existentes e inseridas nas práticas em saúde.

A mistura de gases oxigênio $\left(\mathrm{O}_{2}\right)$ e ozônio $\left(\mathrm{O}_{3}\right)$, com finalidade terapêutica, tem sido empregada como método alternativo nos consultórios odontológicos, como opção a complementar diferentes tipos de procedimentos, sendo considerada minimamente invasiva e conservadora. Em razão das suas características estruturais, molécula triatômica de estrutura cíclica, são múltiplas as aplicabilidades da Ozonioterapia nas áreas/especialidades odontológicas, como Cirurgia - auxílio no processo de reparação tecidual, Dentística - tratamento da cárie, Periodontia - prevenção e tratamento dos quadros inflamatórios/infecciosos, Endodontia - potencialização da fase de sanificação do sistema de canais radiculares, e em conjunto com outras técnicas a fim de potencializar os resultados (BRASIL, 2015).

Diversas são as propriedades do ozônio que propiciam múltiplas aplicabilidades e indicações na odontologia. Logo, tendo em vista a importância de compreender melhor a capacidade preventiva e terapêutica do ozônio para a saúde, objetivou-se uma revisão de literatura com o propósito de descrever sobre a aplicabilidade da

DOI: 10.25110 /arqsaude.v24i3.2020.7950

${ }^{1}$ Acadêmica do $2^{\circ}$ ano do curso de Odontologia (UNIPAR). leisle.p@edu.unipar.br

${ }^{2}$ Acadêmica do $4^{\circ}$ ano do curso de Odontologia (UNIPAR).rafaela.pic@edu.unipar.br

${ }^{3}$ Acadêmica do $2^{\circ}$ ano do curso de Odontologia (UNIPAR). ana.grunow@edu.unipar.br

${ }^{4}$ Acadêmica do $2^{\circ}$ ano do curso de Odontologia (UNIPAR). hperessin27@gmail.com

${ }^{5}$ Acadêmica do $4^{\circ}$ ano do curso de Odontologia (UNIPAR). katiely.tecilla@edu.unipar.br

${ }^{6}$ Professora Titular dos Cursos de Odontologia, Medicina e Mestrado em Plantas Medicinais e Fitoterápicos da UNIPAR - Umuarama. dcboleta@prof.unipar.br 
Ozononioterapia na Odontologia, bem como as formas que a mesma pode ser empregada.

\section{Desenvolvimento}

O Ozônio medicinal, objeto de estudo deste trabalho, é uma mistura de oxigênio $\left(\mathrm{O}_{2}\right)$ e ozônio $\left(\mathrm{O}_{3}\right)$ puros na proporção de $0,05 \%$ a $5 \%$ de $\mathrm{O}_{3}$ e $95 \%$ a $99,95 \%$ de $\mathrm{O}_{2}$ (AZARPAZHOOH; LIMEBACK 2008).

De acordo com o Ministério do Meio Ambiente, a produção do ozônio se dá naturalmente na estratosfera, onde após a ação de raios solares ultravioletas sobre as moléculas de oxigênio, as mesmas se separam e se associam individualmente à outras moléculas de $\mathrm{O}_{2}$.

Segundo Garg e Tandon (2009), a obtenção para fins terapêuticos do ozônio ocorre por meio de três sistemas diferenciados:

a) sistema ultravioleta - fornece concentrações reduzidas de ozônio, sendo comumente usados em tratamentos estéticos, em saunas e na purificação do ar;

b) sistema de plasma frio - é aplicado na purificação do ar e da água;

c) sistema de descarga corona - gera o aumento da concentração de ozônio, através de geradores que imitam os processos da natureza, sendo o mais usual nas áreas médicas e odontológicas por ser de fácil manuseio e permitir taxa de produção do ozônio moderada.

De acordo com o Grupo Philozon (2020), o processo envolvendo os geradores se inicia com uma aplicação de alta tensão entre dois eletrodos, ambiente por onde passa o oxigênio recebendo grandes descargas elétricas, como 15.000 volts ou mais. O término do processo ocorre quando o oxigênio passa entre esses eletrodos e é quebrado, se reagrupando e formando o ozônio.

O ozônio está presente na água em forma molecular, ou seja, como oxigênio triatômico, caracterizando uma solução física. Em temperatura ambiente, essa forma de apresentação é obtida quando usada água bidestilada associada ao gerador de ozônio e fica imediatamente disponível em contato com a pele, ao contrário de outras formas como o óleo ozonizado, que tem efeito retardado (MANJUNATH et al., 2015).

A Associação Brasileira de Ozonioterapia (ABOZ), relata que a água ozonizada também pode ser utilizada de forma tópica e é promissora em bochechos, pois diminui a adesão de placas às superfícies dos dentes, é biocompatível e auxilia no combate à Candida albicans (ABOZ, 2020).

Segundo Kim et al. (2003), o ozônio tem alta capacidade purificadora, responsável por ações microbicidas (bactérias, fungos e vírus). Além disso sua estrutura proporciona características como por exemplo: analgésicas, anti-inflamatórias e imunoetimulantes. Esse gás forma radicais oxidantes na presença de água, que age diretamente sobre os ácidos graxos da membrana celular bacteriana, aumentando a permeabilidade e causando perda de suas funções ao oxidar enzimas, proteínas, DNA e RNA, levando à morte bacteriana

Manjunath, et al. (2015) enfatizam que o ozônio ao reagir com ácidos graxos insaturados presentes na camada lipídica das membranas celulares, forma peróxidos de hidrogênio, sendo estes os indutores de citocinas mais significativas. Para tanto, também age como uma citocina fraca assim como o fator de necrose tumoral- $\alpha$, interleucina-2, interleucina-6, interleucina-8, dentre outros (FERREIRA, 2011; GARDUNO, et al. 1995).

Ademais, possui alta biocompatibilidade, o que propicia a sua aplicação em homens e mulheres de todas as idades.

De acordo com Cardoso et al. (2018), as principais formas de aplicação na odontologia são: água ozonizada, óleo ozonizado e gás ozônio, podendo ser pulverizado ou injetado.

O primeiro registro da utilização do ozônio como tratamento é datado entre 1914-1918, durante a $1^{\circ}$ Guerra Mundial, quando médicos alemães e ingleses o utilizaram para tratar feridas dos soldados (ABOZ, 2020). Para a Odontologia, as primeiras publicações aconteceram em 1934 com o cirurgião-dentista (CD) Edward Fisch que utilizou água ozonizada como antisséptico bucal ao realizar cirurgias orais, também no tratamento de feridas cirúrgicas, com o objetivo de aumentar a quantidade de oxigênio, contribuindo assim com o processo de reparo devido à oxigenação local, além de utilizá-la no tratamento de alvéolos e de canais (Conselho Regional de Odontologia de São Paulo, 2019).

Assim como a aplicação tópica da água ozonizada é viável, observou-se, após análises de cicatrizações de feridas cutâneas, que a aplicação tópica de óleo ozonizado é satisfatória, pois promove, no local da lesão, a síntese de colágeno e a proliferação de fibroblastos, células mais comuns do tecido conjuntivo que irão auxiliar na produção de matriz celular e, consequentemente, cicatrização do tecido lesionado (KIM et al., 2009).

Esses dados demonstram a vasta aplicabilidade da Ozonioterapia nas diversas áreas da Odontologia, o que será esmiuçado a seguir.

\section{Cirurgias Orais}

O ozônio produz oxigênio como subproduto, por meio do aumento da taxa de glicose e glóbulos vermelhos, elevando a taxa de oxigênio que chega aos tecidos, de forma a gerar e estimular enzimas que captam radicais livres e protegem as paredes celulares e, consequentemente, incentivam a reparação tecidual, o que permite a sua utilização como antisséptico em cirurgias bucais (AZARPAZHOOH; LIMEBACK, 2008; ELVIS; EKTA, 2011; NESI, 2018).

Outrossim, o aumento da oxigenação normaliza a microbiota bucal, aumentando a circulação sanguínea e induzindo a formação de células imunocompetentes e imunoglobulinas, que, por sua vez, encerra a inflamação, maximizando a atuação do sistema imunológico. Isso permite que o ozônio tenha efeito em recuperações pós-operatórios em geral e no tratamento de complicações pós cirúrgicas como alveolite, peri-implantite, inflamações exacerbadas ou necroses (AHMEDI et al. 2016).

Elvis e Ekta (2011) indicaram que o ozônio, em concentrações entre 30 e $55 \mu \mathrm{g} / \mathrm{ml}$, causa o estímulo de interleucina 2, que gera ativação do sistema imunológico do paciente como resposta frente à agentes patológicos, além de promover, através da aplicação local, propriedades anti-inflamatórias, atuando na neutralização de mediadores neuroquímicos da sensação dolorosa, facilitando a metabolização e eliminando mediadores inflamatórios, 
como por exemplo histamina e quinina. Além de inibir a cicloxigenase II, evidenciando a redução da permeabilidade celular, edema e dor.

\section{Dentística}

No que se refere à área da Dentística, a capacidade que o ozônio tem de atuar contra as bactérias gram-positivas presentes no biofilme, pode impedir o acometimento inicial da cárie. De acordo com Rodrigues et al. (2010) "o ozônio é uma alternativa, por apresentar propriedades comprovadas na inibição e/ou destruição de diversas bactérias da cavidade bucal - tais como Streptococcus mutans, Streptococcus sanguis e Actinomyces odontolyticus".

Nogales et al. (2008) e Stubinger et al. (2006), afirmam que como resultado do efeito bactericida o ozônio age estabilizando momentaneamente a evolução da lesão de cárie, ocasionando em prevenção ou até mesmo levando ao retardamento da necessidade do tratamento restaurador.

Além disso, Rodrigues et al. (2010) apontam que o ozônio atua na diminuição da acidez do biofilme, gerada por bactérias cariogênicas, o que possibilita a difusão de íons, cálcio e fosfatos nas lesões, e permite a remineralização da dentina e esmalte afetados. Por outro lado, ele modifica o ácido pirúvico e forma o ácido acético, que irá agir como tamponante do ácido cariogênico, desse modo, não é necessário aplicar todo o protocolo previsto para remoção do tecido cariado (AHMEDI et al., 2016).

Com relação ao seu efeito antimicrobiano frente às bactérias do grupo Streptococcus mutans - microrganismo que se apresenta em maior quantidade na cavidade bucal e detêmse da capacidade de produzir ácido capaz de desmineralizar o esmalte dentário, viabilizando o desenvolvimento da cárie, Baysan et al. (2000), classificaram, a partir da utilização da água ozonizada, os resultados de lesões primárias de cárie radicular, que após averiguação dos resultados obtidos, foi possível observar uma considerável redução das amostras de lesões de cárie.

Todavia, Baysan e Beighton (2007) não obtiveram, em seus estudos, resultados satisfatórios em lesões de cárie não cavitadas, considerando a utilização de ozônio na forma de gás, pressupondo que o ozônio não seja efetivo como bactericida se aplicado ao biofilme.

Levando em consideração o tratamento mais comumente utilizado para cárie, que consiste em inserir material restaurador no interior da cavidade, após a remoção do tecido comprometido, a forma mais indicada para aplicação do ozônio é a gasosa ou na forma de água ozonizada, para limpeza da cavidade (NAIK et. al. 2016).

Ainda, com relação ao benefício do ozônio em forma de gás, um estudo preliminar realizado por Knight et al. (2008), demonstrou que a infusão do ozônio gasoso na dentina não cariada preveniu a formação, in vitro, de biofilme de Streptococcus mutans por um período de quatro semanas.

Além da eficácia frente à lesões cariosas já instaladas, Al Shamsi et al. (2008) enfatizam que a aplicação prévia do ozônio sobre o esmalte para a eliminação e controle de microrganismos envoltos à braquetes ortodônticos não prejudica a força adesiva de compósitos resinosos, o que permite um maior controle da atividade cariogênica em pacientes que fazem uso de aparelho ortodôntico.
Nagayoshi et al. (2004) examinaram o efeito da água ozonizada contra infecções por E. faecalis e $S$. mutans e encontraram uma redução significativa na viabilidade desses organismos invadindo os túbulos dentinários.

A terapêutica com ozônio pode ser utilizada como tratamento não invasivo da lesão inicial de cárie ou em lesões cavitadas, visando a descontaminação do tecido dentinário remanescente infectado no preparo dental. Existem evidências sobre a efetividade da atuação do ozônio como um tratamento antimicrobiano profilático antes do condicionamento ácido e da aplicação de selantes e restaurações, obtendo-se resultados positivos, sem interferência nas propriedades físicas do esmalte ou dos materiais restauradores adesivos (TORRES et al. 2013).

A terapia com ozônio foi introduzida como alternativa conservadora no tratamento da cárie incipiente quando um dispositivo gerador de ozônio - HealOzone X4, produzido inicialmente na Alemanha pela empresa Kavo, foi utilizado para aplicar ozônio gasoso em lesões de cárie por um período de 10 a 20 segundos in vivo resultando na redução do número de microrganismos presentes nas lesões em 99\% (BAYSAN; LYNCH, 2006).

O ozônio não é tóxico quando administrado na quantidade de 0,05 ppm por 8 horas. Durante a terapia com ozônio, uma concentração ozônio na cavidade oral é de 0,01 ppm. (GUPTA; MANSI, 2012).

Utilizando água ozonizada em baixas concentrações entre 0,069 a 0,138 ml de ozônio, Baysan, Whiley e Lynch (2000) demonstraram que a exposição de dentina cariada ao ozônio diluído em água pôde em um período de 10 a 20 segundos reduzir os níveis totais de microrganismos a menos de $1 \%$ dos valores controle. Presumivelmente os autores acreditam que o ozônio se dissipou rapidamente pela água e por um mecanismo de ruptura das membranas citoplasmáticas exerceram seu efeito bactericida.

Entretanto, a literatura não apresenta trabalhos que demonstrem a eficácia da água ozonizada usada como agente antibacteriano contra microrganismos nos túbulos da dentina.

\section{Periodontia}

Domb (2014) comprovou a eficácia do ozônio em doenças periodontais, o que se dá por meio do controle bacteriano efetivo contra todas as bactérias orais testadas com o $\mathrm{O}_{3}$, podendo ser aplicado diretamente nos sulcos, nos abscessos ou em áreas de infecções, nas formas de óleo ozonizado, água ozonizada ou gás.

O ozônio mostra ser eficaz sobre a microbiota subgengival, atuando na diminuição do sangramento e da profundidade à sondagem. Tanto em processos crônicos periodontais quanto em processos agudos, o uso do ozônio tem demonstrado ser bastante satisfatório. O uso da água ozonizada em bochechos diminui a adesão de placa à superfície dental e ao mesmo tempo neutraliza totalmente culturas de Staphylococcus aureus (HUTH, et al., 2006).

Além da diminuição da adesão de placa, a irrigação subgengival com água ozonizada permite o restabelecimento da higiene oral por meio da eliminação de agentes etiológicos. Iliadis e Millar (2013) relataram maior redução no índice de placa e índice gengival, seguindo o uso de irrigação de ozônio, quando comparado com o uso de outros meios, como 
por exemplo a clorexidina.

O Ozone Dental Group (2019) mostra que em quadros de periodontite, a Raspagem e Polimento Coronário Radicular (RPCR) apresentam resultados mais efetivos quando realizada com o ozônio na forma de óleo, aplicado na bolsa periodontal e seguida pela raspagem associada à irrigação com água ozonizada, além de infiltração do gás ozônio na bolsa. Tal protocolo culmina com a reinserção das fibras do ligamento periodontal à superfície radicular mais rapidamente, quando comparado com o protocolo tradicional.

No entanto, referente à utilização do ozônio em forma de gás, há a necessidade de se obter um sistema mais seguro para sua aplicação na bolsa periodontal, a fim de evitar a inalação e possível intoxicação do paciente (HUTH et al., 2011). Portanto, é de suma importância que a concentração de ozônio seja de 40-70 $\mu \mathrm{g} / \mathrm{ml}$, considerando o estágio da doença, bem como, a condição sistêmica do paciente que está sendo submetido ao tratamento (BOCCI; ALDINUCCI, 2006).

Outrossim, a terapia com ozônio elimina os patógenos causadores da doença periodontal, restaurando o metabolismo, adequando o nível do oxigênio e normalizando a microbiota periodontal, aumentando a circulação sanguínea e ativando o sistema imunológico (GARG; TANDON, 2009).

Contudo, no decorrer da ativação do sistema imunológico, há a proliferação de células imunocompetentes, síntese de imunoglobulinas, aumento da sensibilidade dos microrganismos à fagocitose e ativação da função de macrófagos. Tais mecanismos de ação, que resultam em efeitos de imunoestimulação, só são obtidos na presença de baixas concentrações de ozônio, do contrário, o seu efeito é imunodepressor (NAIK et al. 2016; SRIKANTH et al. 2013).

Dessa forma, para tratamentos periodontais, devese considerar que o ozônio apresenta-se como um tratamento terapêutico viável e considerável, desde que mais estudos randomizados sejam realizados (com acompanhamento por mais tempo) e que, ao mesmo tempo, se considere causas multifatoriais, além de associar a condição sistêmica do paciente e o possível risco de toxicidade.

\section{Endodontia}

$\mathrm{Na}$ endodontia, a principal bactéria envolvida nos casos de insucesso no tratamento de canais radiculares é o Enterococcus Faecalis, e quanto a isso, o ozônio tem se mostrado eficiente na redução/eliminação da referida bactéria (SUSHMA, 2011).

Ao mesmo tempo, mostra-se eficaz contra vírus e fungos encontrados nas raízes contaminadas, as quais são submetidas, posteriormente, à tratamentos endodônticos. À vista disso, eleva consideravelmente a taxa de êxitos em tratamentos e retratamentos endodônticos (SUSHMA, 2011).

Gupta e Mansi (2012) contextualizam que o ozônio é empregado durante o preparo dos canais, tanto na forma de gás, água ozonizada como irrigante, semelhante à aplicada em tratamentos periodontais, e óleo ozonizado quanto medicação intracanal, podendo ser utilizados individualmente ou em combinação.

Entretanto, um estudo realizado por Cardoso et al. (2008), revelou que as endotoxinas presentes nas bactérias gram-negativas, como lipopolissacarídeos (LPS), e que também são responsáveis pelas falhas dos tratamentos endodônticos, não foram neutralizadas pela utilização da água ozonizada e, por isso, existe a preocupação com a ação citotóxica que pode ocorrer ao entrar em contato com células da região apical. Além do mais, demonstrou que a água ozonizada reduziu significativamente o número de Enterococcus Faecalis, porém, após sete dias, foram identificados valores aumentados.

No que se refere à biocompatibilidade do ozônio, Hult et al. (2006) mostram que na sua forma aquosa, o ozônio não revelou essencialmente nenhum efeito tóxico, apresentando melhor biocompatibilidade do que a clorexidina $0,2 \%$. Além da biocompatibilidade e do potencial antimicrobiano, o ozônio ajuda e estimula a regeneração apical, devido à maior oferta de oxigênio para os tecidos, diminuindo, assim, a necessidade de cirurgias periapicais (ALMEIDA et al., 2019).

A administração tópica do ozônio pode ser feita de duas formas: aberta ou por sucção vedada (para que não haja inalação e efeitos colaterais aos pacientes) (GUPTA, MANSI 2012).

As vantagens do alótropo, empregado através da Ozonioterapia, nos tratamentos endodônticos, se caracterizam, principalmente, por representar um tratamento altamente biológico, indolor ao paciente e por ser coadjuvante ao tratamento convencional (ALMEIDA et al., 2019).

Mesmo com benefícios comprovados por meio da literatura, ainda há a necessidade de estudos clínicos controlados que possam determinar os limites de aplicação e, como essa prática pode ser empregada de forma segura.

\section{Contraindicações}

Nogales et al. (2009) afirmam que, em razão do poder oxidativo do ozônio, todos os materiais em contato com o gás devem ser ozônio-resistentes, como vidro, silicone e Teflon. Além da administração, que deverá ser feita no próprio local, não podendo ser transportado ou armazenado após a conversão de oxigênio para ozônio.

Por ser uma molécula triatômica, o ozônio é muito mais instável e com ação mais seletiva sobre componentes orgânicos, possui um tempo de vida média de $40 \mathrm{~min}$ a $25^{\circ} \mathrm{C}$ e a partir desse tempo se decompõem em oxigênio em uma velocidade dependente da temperatura ambiente, quanto maior a concentração e maior a temperatura, maior a dissociação (BULIÉS et al., 1997; BOCCI, 2004).

Martinez (2013), demonstrou a importância de usar o gás nos primeiros 10 minutos depois de gerado, no qual $10 \%$ da dose inicial é perdida.

Os tratamentos com ozônio apresentam um grau de complicação irrisório quando realizados em pequenas doses para fins terapêuticos. Contudo, a aspiração do ozônio em quantidades elevadas pode ser danosa ao sistema respiratório. A alta capacidade de oxidação do ozônio, acarreta uma cascata de peroxidação de lipídios e ácidos graxos presente nas células de revestimentos pulmonares, liberando mediadores endógenos de inflamação (SILVA; DRUMMOND, 2019).

Em caso de intoxicação, o paciente deve ser deitado, fazer inalação com oxigênio umidificado e administrar ácido ascórbico, vitamina E e acetilcisteína. Além dos efeitos principais, como no caso da intoxicação, também podem ser 
observados efeitos secundários, como: olhos lacrimejantes, irritação do trato respiratório, rinite, tosse, enxaqueca, náuseas e vômito (NOGALES et al., 2009).

Do mesmo modo, deve-se ter atenção especial em casos de gravidez, anemia grave, intoxicação ao álcool aguda, pessoas com deficiência da glicose-6-fosfato desidrogenase, hipertireoidismo, hipoglicemia, em quadros de hemorragia e alergia ao ozônio (SUSHMA, 2011).

Sebbah et al. (2018) ressaltam que, embora os resultados de tratamentos com ozônio sejam extremamente positivos, é necessário verificar os protocolos de aplicação e concentração indicados a serem seguidos. Portanto, padronizações referentes ao tempo e a dosagem, são de suma importância, visto que cada gerador possui uma concentração ideal de acordo com seu fabricante e que é imprescindível que cada patologia inerente à cavidade oral disponha da melhor terapêutica.

\section{Considerações Finais}

Atualmente, os principais obstáculos para disseminação da Ozonioterapia, é a escassez de recursos destinados para pesquisas, a recente aprovação pelo Ministério da Saúde, o que gera uma certa hesitação e a resistência da indústria farmacêutica, e os custos dos equipamentos que podem variar de $\mathrm{R} \$ 2.000,00$ a $\mathrm{R} \$ 8.000,00$.

É requisito para habilitação, conclusão de curso de formação específico com certificação expedido por uma instituição de ensino superior devidamente registrada no Ministério da Educação com conteúdo programático da habilitação em Ozonioterapia aplicada à Odontologia, não há muitos cursos disponíveis com estas características.

Face ao exposto, compreende-se que os benefícios do ozônio são comprovados, porém, carece de mais estudos randomizados a fim de determinar seus riscos potenciais, principalmente frente à toxicidade, assim como, a viabilidade de seu uso se comparado às terapêuticas já existentes. É de suma importância que parâmetros de uso e de segurança sejam bem definidos independente da especialidade a ser aplicado.

\section{Referências}

AHMEDI, J. et al. Efficiency of gaseous ozone in reducing the development of dry socket following surgical third molar extraction. Eur. J. Den. v. 10, n. 3, p. 381-385, 2016.

ALMEIDA, K. D. O. et al. Ozonioterapia: o uso de ozônio da endodontia. In: SALÃO DE ENSINO E EXTENSÃO, INOVAÇÃO NA APRENDIZAGEM, 2019, Santa Cruz do Sul. Anais ... Disponível em: http://online.unisc.br/acadnet/ anais/index.php/salao_ensino_extensao/article/view/19992. Acesso em: 10 mar. 2020.

AL SHAMSI, A. H. et al. The effects of ozone gas aplication on shear bond strenght of ortodontic brackets to enamel. American Journal of Dentistry, v. 21, n. 1, p. 35-38, 2008.

ASSOCIAÇÃO BRASILEIRA DE OZONIOTERAPIA (ABOZ). História da ozonioterapia. Disponível em: https:/www.aboz.org.br/multiprofissional-interdisciplinar/ odontologia/. Acesso em: 26 fev. 2020.

AZARPAZHOOH, A.; LIMEBACK, H. The application of ozone in dentistry: a systematic review of literature. Journal of Dentistry, v. 36, n. 2, p. 104-116, 2008.

BAYSAN, A.; WHILEY, R. A.; LYNCH, E.

Antimicrobial effect of a novel ozone generating device on microorganisms associated with primary root carious lesions in vitro. Caries Res. v. 34, n. 6, p. 498-501, 2000.

BAYSAN, A.; BEIGHTON, D. Assessment of the ozone mediated killing of bacteria in infected dentine associated with non-cavitated occlusal carious lesions. Caries Res. v. 41, n. 5 p. 337-341, 2007.

BAYSAN, A.; LYNCH, E. The use of ozone in dentistry and medicine: part 2. Ozone and root caries. Prim. Dent. Care, v. 13, n.1, p. 37-41, 2006.

BOCCI, V. A. How ozone acts and how it exerts therapeutic effects. In: Autoria. Lynch E. Ozone: the revolution in dentistry. Surrey: Quintessence. 2004. p. 15-22.

BOCCI, V.; ALDINUCCI, C. Biochemical modifications induced in human blood by oxygenation-ozonation. J. Biochem. Mol. Toxicol. v. 20, n. 3, p.133-8, 2006.

BRASIL. Portaria $n^{\circ}$ 971, de 03 de maio de 2006. Aprova a Política Nacional de Práticas Integrativas e Complementares (PNPIC) no Sistema Único de Saúde. Diário Oficial [da] República Federativa do Brasil, Brasília, DF, 04 maio 2006. Disponível em: http://bvsms.saude.gov.br/bvs/saudelegis/ gm/2006/prt0971_03_05_2006.html. Acesso em: 09 mar. 2020 .

BRASIL. Resolução nº 166, de 24 de novembro de 2015. Reconhece e regulamenta o uso pelo cirurgião-dentista da prática de Ozonioterapia. Diário Oficial [da] República Federativa do Brasil, Brasília, DF, 08 dez. 2015. Disponível em: https://pesquisa.in.gov.br/imprensa/jsp/visualiza/index. jsp? jornal $=1 \&$ pagina $=95 \&$ data $=08 / 12 / 2015$. Acesso em: 09 mar. 2020.

BULIÉS, J. C. et al. Resultados terapéuticos en la osteoartritis de la rodilla con infiltraciones de ozono. Rev. Cubana Invest. Biomed. v. 16, n. 2, p. 124-32, 1997.

CARDOSO, I. et al. Alternativa de tratamento com ozonioterapia para recorrências do herpes vírus labial relato de caso. Psicologia e Saúde em Debate, v. 4, n. 1, p. 41-41, 2018.

CARDOSO, M. G. et al. Effectiveness of ozonated water on Candida albicans, Enterococcus faecalis, and endotoxins in root canals. Oral Surg. Oral Med. Oral Pathol. Oral Radiol. Endod. v. 105, n. 3, p. 85-91, 2008. 
Odontologia. 2019. Disponível em: http://www.crosp.org. br/noticia/ver/3504-Esclarecimentos-sobre-Ozonioterapiana-Odontologia.html. Acesso em: 28 fev. 2020.

DOMB, W. C. Ozone therapy in dentistry. A brief review for physicians. Interventional Neuroradiology, v. 20, n. 5, p. 632-636, 2014.

ELVIS, A. M.; EKTA, J. S. Ozone therapy: a clinical review. J. Nat. Sci. Biol. Med. v. 2, n. 1, p. 66-70, 2011.

FERREIRA, M. B. Efeito na reparação óssea periapical da ozonioterapia como coadjuvante ao tratamento endodôntico. 2011. Tese (Doutorado em Ciências Odontológicas) - Faculdade de Odontologia da Universidade de São Paulo, São Paulo, 2011.

GARDUNO, P. G. et al. Efectos del agua ozonificada en la placa dento bacteriana. Assoc. Dent. Med. v. 52, n. 6, p. 305-308, 1995.

GARG, R. K.; TANDON, S. Ozone: a new face of dentistry. Internet J. Dent. Sci. v. 7, n. 2, p. 295-297, 2009.

GRUPO PHILOZON. Como o ozônio é produzido?. Disponível em: http://www.philozon.com.br/noticias/comoo-ozonio-e-produzido/. Acesso em: 15 fev. 2020.

GUPTA, G.; MANSI, B. Ozone therapy in periodontics. Journal of Medicine and Life. v. 5, n. 1, p. 59-67, 2012.

HUTH, K. C. et al. Effect of ozone on oral cells compared with established antimicrobials. Eur. J. Oral Sci. v. 114, p. 40-435, 2006.

HUTH, K. C. et al. Effectiveness of ozone against periodontal pathogenic microorganisms. Eur. J. Oral Sci. v. 119, n. 3, p. 204-210, 2011.

ILIADIS, D.; MILLAR, B. J. Ozone and its use in periodontal treatment. Open Journal of Stomatology, v. 3, p. 197- 202, 2013.

KIM, J. G.; YOUSEF, A. E.; KHADRE, M. A. Ozone and its current and future application in the food industry. Adv. Food Nutr. Res. v. 45, p. 167-218, 2003.

KIM, H. S. et al. Therapeutic effects of topical application of ozone on acute cutaneous wound healing. J. Korean. Med. Sci. v. 24, n. 3, p. 368-374, 2009.

KNIGHT, G. M. et al. The inability of Streptococcus mutans and Lactobacillus acidophilus to form a biofilm in vitro on dentine pretreated with ozone. Australian Dental Journal, v. 53, n. 4, p. 349-353, 2008.

MANJUNATH, R. G. S.; SINGLA, D.; SINGH, A. Ozone Revisited. Int. J. Adv. Res. v. 6, n. 2, p. 5-9, 2015.

MARTINEZ, G. S. Aspectos prácticos en ozonoterapia: Comprobación de la concentración de ozono generada / tiempo de vida media del gas en la jeringuilla. Revista Española de Ozonoterapia, v. 3, n.1, p. 67-73, 2013.

NAGAYOSHI, M. et al. Antimicrobial effect of ozonated water on bacteria invading dentinal tubules. Journal of Endodontics, v. 30, n. 11, p.778-781, 2004.

NAIK, S. V. et al. Ozone: a biological therapy in dentistry reality or myth? Open Dent. J. v. 10, n.1, p. 196-206, 2016.

SRIKANTH, A.; SATHISH, M.; HARSHA, A. V. S. Application of ozone in the treatment of periodontal disease. Journal of Pharmacy and Bioallied Sciences, v. 5, n.1, p. 89-94, 2013.

NESI, A. K. OZONIOTERAPIA: o uso do ozônio da odontologia. 2018, 24 f. Monografia (Conclusão de Curso) Centro Universitário São Lucas, Porto Velho, 2018.

NOGALES, C. G. et al. Avaliação da ação da água ozonizada frente a bactérias encontradas em casos de periodontite apical secundária persistente. Braz. Oral Res. v. 23, n.1, p. 188, 2009.

NOGALES, C. G. et al. Ozono therapy in medicine and dentistry. J. Contemp. Dent. Pract. v. 9, n. 4, p. 75-84, 2008.

OZONE DENTAL GROUP. A ozonioterapia. 2019. Disponível em: http://cursoozonioterapia.com.br/ ozonioterapia/. Acesso em: 13 mar. 2020.

RODRIGUES, P. C. F. et al. Abordagens sobre o ozônio no tratamento de lesão cariosa e em procedimento restaurador adesivo. Rev. Dental Press de Estét. v. 7, p.74-80, 2010.

SEBBAH, F. et al. Ozonetherapy in dentistry - where we are and where we are going to? Revista Española de Ozonoterapia, v. 8, n. 1, p. 37-63, 2018.

SILVA, N. L. S. D; DRUMMOND, V. P. A. Ozonioterapia na Odontologia Revisão de Literatura. 2019. 28 f. Monografia (Conclusão de Curso) - Universidade de Uberaba, Uberaba, 2019.

STUBINGER, S.; SADER, R.; FILIPPI, A. The use of ozone in dentristry and maxillofacial surgery: a review. Quintenssence International, v. 37, n. 5, p. 353-359, 2006.

SUSHMA, D. Application of Ozone therapy in dentistry. Indian. journal of Dental Advancements, v. 3, n. 2, p. 538-542, 2011.

TORRES, C. R. G. Odontologia restauradora estética e funcional: princípios para a prática clínica. Santos, 2013. $744 \mathrm{p}$.

Recebido em: 08/02/2020 Aceito em: 05/10/2020 